\title{
Arab EFL Learners' Writing Dilemma at Tertiary Level
}

\author{
El-Sadig Ezza \\ Al-Majma'ah University \\ Kingdom of Saudi Arabia \\ E-mail: sadigss@yahoo.com
}

\begin{abstract}
There is a general belief among researchers and speakers at conferences and symposia that Arab EFL Learners are primarily responsible for their weak writing performance. Educational policies usually evade criticism. This study is an attempt to show that educational policies can have their role in the learner's writing problems. Viz. it posits that for the most part writing problems can be caused by the employment of outdated approaches and resources. To this end, content analysis has been applied to existing writing courses in three Arab Universities. The examination of these courses has revealed that English Departments adopted approaches and materials characteristic of the 1940s and 1950s. Thus, unless the new the developments into the linguistic and writing theories and approaches are incorporated into the writing syllabus, Arab EFL learners will continue to experience writing problems.
\end{abstract}

Keywords: Writing approaches, Syllabus, Communicative competence, Writing pedagogy, Functional approach, Context, Text-linguistics, Bottom-up

\section{Introduction}

Research into Arab EFL learners' writing centres for the most part upon learner's failure to handle a variety of assignments as prescribed by the syllabus that has constituted their language training. Other things being equal, writing problems are primarily attributed to the students' linguistic incompetence, immature mastery of rhetorical structure of the English text, Arabic discourse transfer and the like (Al-Khuweileh and Al-Shoumali, 2000; Al-Hazmi and Schofield, 2007; Fitze and Glasgow, 2009). Implicit in such research findings is the suggestion that learners are to blame for their failure to rise to the expectation of their institutions. Apparently, educational policies have seldom been rendered responsible for defects in learning output in general and demonstration of writing skills in particular. Viz. Such factors as teacher/student ratio, the number of students in the classroom, the number of writing courses, course materials, teaching methodology, etc. have rarely been addressed as possible causes of Arab EFL learners' writing problems. This paper posits that the institutional adoption of outdated writing approaches, and, therefore, the use of writing resources pertaining to them are the main factors to complicate Arab EFL learners' writing practice. In that connection, the paper will apply content analysis to these areas in three Arab Universities: King Saud University (Saudi Arabia), Jordan University of Science and Technology (Jordan) and Al-Akhawayan University (Morocco).

\section{Theoretical Background}

Generally speaking, part of the dilemma of writing pedagogy lies with the way it has historically been approached vis-à-vis the other language skills. For example, take the formal and functional definitions of writing. Formally, writing is conceived as the 'recording of human communication, using signs or symbols to represent the spoken words' (McMillan Encyclopedia, 1986:1317) while it is defined functionally as a 'curiously solitary form of communication, addressed to an absent and often unknown reader' (Peters, 1986:169). Both definitions seem to put writing at disadvantage since it is either seen as a secondary activity to reinforce speech or rendered somehow desocialized form of communication. Indeed, during the audio-lingual era, the teaching of writing, technically known as controlled composition, was conceived to function as a service activity to reinforce listening and speaking skills (Freedman et al, 1983; Silva, 1990; Rivers, 1981).

However, there are three arguments supporting the fact that the fate of writing is not always bound up with the fate of the other skills. First, people do not always use writing to reinforce activities pertaining to other skills being learned. In fact, there are a number of activities that can only be handled through the medium of writing. Viz. such activities as personal and official letters, books, newspapers, journals, etc could not be conceived as just a reflection of other skills in any direct sense. Nor can it be possible to argue that these skills are as capable as writing in handling these same communicative functions. Even in educational settings there are situations where students practise writing as an end in itself. Second, there are a variety of writing problems that cannot be overcome by learners' competence in the other skills. This could have otherwise been the case if writing had indeed been approached simply as 'homemaid' of the other skills. The writing literature shows that it is mostly through writing instruction, writing practice and teacher's feedback that students' writing can be improved (cf. Krashen, 1984). 
Third, writing autonomy can be shown by its role as a differentiating factor between literate and illiterate members of the relevant speech community.

Regardless of the changing roles that writing has been assumed to play (cf. Raimes, 1987), a number of approaches have to date been proposed to provide guidelines for (successful) writing pedagogy. The relevant literature abounds in three such approaches that seem to have been most influential. These are the product approach, the process approach and the functional approach. As to the process approach, it is concerned with the finished text. Particularly, it is concerned with manipulation of lexical and grammatical structures in the written text. All writing forms characteristic of the oral and audio-lingual methods (technically known as controlled composition) are subsumed under this approach since they were concerned with the correct use of language structures. Of course, these forms of writing could not be expected to develop learners' composing abilities beyond the sentence level. What they did was either reinforce 'paradigms, grammatical exercises, dictation, translation from native to target language' (Rivers, 1981:293) or functioned as a reinforcement for oral habits (Silva, 1990:11).

However, the 1960s witnessed a new development into the product approach that has come to be known in the literature as the 'current-traditional rhetoric'. This writing theory differs from its predecessor (i.e. controlled composition) in advocating writing at discourse level. It particularly emphasized the paragraph and its components (ibid, p. 14). According to Connor (1996: 59), current-traditional rhetoric benefited writing in three ways. First, 'written products became a respectable object of academic enquiry'. Second, writing was no longer taught by part-time instructors or Teaching Assistants. Third, a number of journals were devoted to research in writing. All in all, current traditional rhetoric contributed to free writing from being a mere reinforcement of its sister skills; viz. writing has become an independent skill and has been practiced for its own sake.

However, the product approach became a subject of criticism in 1980s. For example, Freedman et al (1983:181) conceive of it as 'pedagogically weak' for the insufficient attention it paid to the writing stages. On the other hand, Zamel (1983:165) argues that the product approach was 'prescriptive, formulaic, and overtly concerned with correctness'. A most comprehensive criticism comes from Krashen (1984:25). He maintains that if the student-writer is 'able to master all the rules of punctuation, spelling, grammar, and style that linguists have discovered and described', then their reward would be a Ph.D in Linguistics but they would never be competent in writing.

So owing to what was considered drawbacks in the product approach, the late 1970s witnessed a shift to the process approach. From the point of view of the advocates of the new approach, writing should be an 'explanatory and generative process whereby writers discover and reformulate their ideas as they attempt to approximate meaning' (Zamel, 1983:165). According to Raimes (1983:216) 'composing means expressing ideas, conveying meaning; composing means thinking'. Obviously, then, the manipulation of linguistic structures would be considered the most peripheral aspect of writing. In fact, by preoccupying themselves with the formal aspects of writing, the students would do no more than 'lock themselves into a semantic and rhetorical prison' (ibid). Instead, the prime concern for classroom activities would, therefore, be generating preliminary ideas, doing prewriting activities, outlining, getting started, producing first drafts, editing, revising, etc. (Jordan, 1997:167).

As it was the case with its predecessor, the process approach came under severe attack by the functionalists. Other things being equal, it has been argued to 'overemphasize the individual psychological functioning and neglect the socio-cultural context', it, therefore, 'operates in a socio-cultural vacuum'. Thus, due to these considerations, the late 1970s witnessed a shift to a new direction in writing pedagogy where more attention was paid to the social (and cultural) context of writing. The relevant literature abounds in a number of approaches that focus on the sociolinguistic and socio-cultural dimensions of writing. These include the communicative approach, the functional approach and the genre approach, to mention but some. For the most part, the difference between these approaches is terminological in nature, and it is often the case that, say, the genre approach is subsumed under the functional approach while the communicative and functional approaches are two facets of the same fact, i.e. the communicative function of human language. However, since the functional approach is conceived to be a pure theory of writing (cf. Couture, 1986), it will be adopted for review in this paper.

To begin with, the functional approach has its origin in Halliday's systemic theory, which was developed out of linguists dissatisfaction with the structural and transformational models that dominated language study and education during the first half of the $20^{\text {th }}$ century. Together with its sister theory of communicative competence (Hymes, 1979), the systemic theory is acknowledged to have introduced dramatic changes that have continued to shape language study and education. Linguists, therefore, language educators have concluded that the structural and transformational view of language does not adequately account for language as a system of communication. According to Connor (1996:80) 'the resulting field has been given a variety of names: text linguistics, written discourse analysis, and discourse linguistics'. Although these terms, Connor reports, 'are used interchangeably in the literature ... recent publications treat text linguistics as written, not spoken discourse analysis ...'. 
Now since knowledge of the text is not enough to enable language users communicate successfully, a set of socio-cultural constraints have been incorporated into the linguistic theory to guarantee more effective communication. In that connection, Hymes (1979): maintains that acquisition of linguistic competence 'has to be fed by social experience, needs and motives'. More specifically, Brandt (1986:94) argues that 'since a text grows out of a situation, it reflects that situation in its lexical and linguistic structure'.

The systemic theory has particularly been argued to have far-reaching consequences for writing pedagogy. Couture (1986:1) proposes that 'the systemic view of language as social semiotic has dramatic consequences for scholarly investigation of written discourse' in three ways. First, writing researchers should 'reconsider the explanation of language as lexical and syntactic components; rather they should approach it 'as textual explanation that must account for the semiotic systems that language creates, and extra-textual meanings referenced by language' (p.2). Second, writing researchers should approach the text as a 'communicative event rather than something that illustrates a theoretical point'. Third, researchers 'must seek heuristic universals in explaining textual functions' i.e. they should develop a functional language theory that 'unites the speakers, listeners and situation'

\section{Research into Arab EFL Learners' Writing}

As to empirical research into Arab EFL learners' writing, it falls into two categories as illustrated by the studies that have been selected for review: cross-cultural studies and instruction-oriented studies. Of course, these categories are not mutually-exclusive since all the studies address the same theme: Arab EFL learners' writing. As to the first category, there are three studies that attempted to approach learners' writing cross-culturally. First, Al-Jamhoor (2001) applied cross-cultural analysis to the writing of Arab-speaking Learners of English. He particularly researched writing problems that were perceived to face Arab EFL learners at Imam University, Saudi Arabia. Fifty students were asked to write essays in English and Arabic. These essays were, then, compared to essays written by a control group, consisting of fifty American students at Michigan State University. The researcher concluded that the Arabic speaking students used fewer conclusions, $t$-units but more discourse units than their American counterparts did. Since the research did not start from a clear-cut pedagogical objective, it is uncertain if these findings can be employed to support a call for specific educational procedures to improve learners' composing competence.

The second study was conducted by Al-Khuweileh and Al Shoumali (2000); they set out to investigate the 'association between poor writing in English and Arabic'. Data was collected from the writing of 150 students at Jordan University of Science and Technology. The results confirmed the generally held belief that poor writing in the mother tongue usually correlates with poor writing in the target language.

Third, Daoud (1998) studied the role of exchange strategies in improving Arab EFL learners' writing skills and in changing their attitude towards the target language culture. The subjects of the study were Syrian ESP medical students at Damascus University. They were required to exchange essays with American counterparts. The subjects were particularly asked to write about 'their personalities, lives, and culture or dealt with issues of international concern' (p.391); such aspects of writing as 'topic sentence, and support were emphasized'. The experiment was implemented within a framework of an ESP course that centres upon the teaching of the four skills. The results showed that the subjects 'lacked appropriate vocabulary and expressions'; also some of them were found to be 'aggressive in addressing their American counterparts' but they were informed by the researcher that 'good writers ... had to find their way to people hearts and minds by presenting convincing arguments supported by concrete details and examples' (p. 397).

The instruction-based category also comprises three studies: Al-Hazmi (2006), Al-Hazmi and Schofield (2007) and Fitze and Glasgow (2009). As to the first study, Al-Hazmi (2006) conducted a study against the background that EFL writing in the Arab world suffers from traditional teaching which renders it 'abstracted, depersonalized and product oriented' (p. 35). These problems, the researcher contends, could only be overcome by applying the guidelines of the process approach to writing pedagogy since it is 'uniquely suited to promoting the skills of critical thinking and self-reflection' (p.36). However, despite all this enthusiasm, all the researcher did was elicit research data using an open-ended questionnaire. There was no written assignment to support the researcher's faith in the strengths of the process approach; the subjects simply answered questions about what an ideal writer would do when drafting a text, knowing that 'their language proficiency in absolute terms can only be termed as pre-intermediate' (p.39); viz. none is an ideal writer!

The second of these studies investigated the effect of enforced revision and peer feedback on the students' writing quality. The study was intended to improve the writing of low-proficiency Saudi Students at tertiary level. A total of 51 third level students at King Khalid University participated in the experiment. At the pretest stage all the subjects wrote two drafts but only the experimental group was provided with a checklist to consider at the post-test stage. The researchers concluded that the subjects 'were not ready to abandon the traditional surface error focus of their classroom' despite the research effort to improve their English writing (p.237). 
The third study is Fitze and Glasgow (2009). An action research was implemented to improve tense formation in Arab EFL writing. The subjects of the study were low-level students at Dubai Women's College, United Arab Emirates. The subjects were instructed in English Grammar and were later required to submit a written assignment. Results indicated that 'grammatical accuracy of students' writing can be notably enhanced by providing teacher-led grammar instruction prior to independent writing'. The problem with his study is that it follows from a bottom-up approach to writing where mastery of linguistic competence is conceived a necessary condition for writing. This could have been the case during the traditional and structural writing practices in the first half of the $20^{\text {th }}$ century but sure enough could not receive theoretical support at post-discourse era.

To conclude this section, all the studies investigated either learner's composing problems or examined their reaction to new techniques for improving their writing skills. Thus, it is possible to claim that the theme addressed by the present study has not been directly considered by previous research.

\section{Methods}

\subsection{Materials}

The research materials consist of detailed description of three writing courses in three Arab Universities: King Saud University (Saudi Arabia), Jordan University of Science and Technology (Jordan) and Al-Akhawayan University (Morocco) as summarized in the table below. These institutions have been selected for three reasons. First, they come from different Arab regions. Second, they belong to the group of top Arab universities both nationally and regionally according to the Spanish ranking of the world universities (technically known as Webo-metrics). Third, unlike many universities in the group, they have posted all the course components needed for this research online.

\subsection{Data}

Data will be elicited from the research materials. It consists of the specific components used for the teaching of writing. Depending on the relevant approach to writing pedagogy, data includes ineralia, word classes, phrases, sentence structures, topic sentence, cohesive devices, techniques of paragraph development, etc.

\subsection{Data Analysis}

After the isolation of the research data, content analysis will be applied to it. In other words, The documents known technically as "courses' description" will be broken down into course components referred to in (3.2) as data that will then be examined in the light of the literature reported in (2) above. .

\section{Results and Discussion}

The following table presents the components of selected writing courses offered by the three English Departments, corresponding to the universities mentioned above (consecutively):

Insert Table 1 Here

The table clearly indicates that these Departments, and possibly many others in the Arab world, conceive of writing from a product approach perspective. Even worse, they advocate the version characteristic of the oral and audio-lingual methods since the primary concern of the writing courses is the sentence and its components. Such a view of writing pedagogy reduces writing to a mere exercise in the English grammar. It was shown in (2) above that linguists have since 1970s abandoned the structural and transformational concept of the sentence as the basic unit of language. Thus, the focus of linguistic enquiry has moved from the sentence to the text as the basic unit of linguistic communication. These developments have enormously revolutionized writing pedagogy in different parts of the world (cf. Couture, 1986; McDonough and Show, 1993) but seem to have fallen on deaf ear in the Arab world since writing course designers still belief in the acquisition of grammar as a key to the mastery of writing skills.

Grammar-based approach to writing, so to speak, can be argued to be defective in three respects. First, grammar is an open-ended phenomenon to the extent that it jeopardizes writing pedagogy. Viz. If the fate of writing is bound up with acquisition of grammar, learners could not be expected to study and practise writing properly and the eight terms of college teaching might not be enough to cover the particularities of grammar - knowing that the bulk of grammar is of no practical use for the students' writing needs, e.g. generating surface structures from deep structures. Second, even when the argument that mastery of grammar determines success in writing is taken for granted, there still remains the question about the nature of grammar needed in the writing programme; for grammar comes in different schools (formal/functional), theories (structural/ transformational), types (theoretical/pedagogical), etc. which are for the most part mutually exclusive, and cannot, therefore, be compromised into a coherent writing programme. Third, emphasizing grammar in a writing course overshadows the nature of writing as a communication skill where grammar is one of many resources that writers resort to in order to enrich their communicative intent. In fact, grammar operates at a linguistic level below that of the basic unit of writing, i.e. the paragraph where emphasis will primarily be on textuality, i.e. the relationship between sentences, rather than grammaticality, i.e. the well-formedness of the sentence (Xu, 1991).

The writing components in the three columns in table (2) strongly justify both the research focus and findings reported in section (3) above. Where the focus is concerned, both types of research (cross-cultural and 
instruction-oriented) explicitly and implicitly considered the linguistic difficulties experienced by the research subjects. It has been argued in this section that linguistic information is open-ended and cannot, therefore, be sufficiently handled even in pure grammar courses, let alone the amount incorporated in the writing courses as illustrated by the ones selected for analysis in this study. Thus, since the role of grammar has been emphasized at the expense of the writing skills, e.g. topic sentence, paragraphing, cohesion, coherence, etc., the students will continue to have writing problems. As to the research findings, it is suffice to point out that Al-Hazmi and Schofield (2007:237) concluded that their research subjects 'were not ready to abandon the traditional surface error focus of their classroom'. It is unfortunate that the students were not properly trained in writing but are still blamed for a job that was never theirs. Sure enough, as long as writing instruction focuses on grammar, traditional writing practice will always shape their writing attempts.

It is important at the end of this section to make a few remarks about the basic resources for the courses under examination. These are: Faulkner (1981) (King Saud University) and Diana (2003) (Jordan University of Science and Technology); (as to third course, the Department compiles its course materials which was not posted on the website). Despite the fact that the two textbooks were published during discourse and post-discourse era, they abound in grammatical descriptions and writing traditions in the manner summarized in table (2) above. Now, since the first textbook openly claims that the 'writing of good sentences' is key to effective composing, it would be legitimate to refute this claim in the light of modern theories of writing.

To begin with, the first edition of Faulkner's book, was contemporary with the transition from the Bloomfieldian linguistics to the Chomskyan linguistics, so to speak. Viz. in that same year (i.e. 1957) Professor Chomsky's 'Syntactic Structures' was published. It was argued to have revolutionized the linguistic theory in North America that was once dominated by American structuralist linguistics as led by Leonard Bloomfield (Harsh 1982). Once more the year 1981 witnessed a striking coincidence of Faulkner's third edition and Chomsky's third version of his transformational grammar, which has come to be known as Government and Binding (GB). This series of coincidences alongside the content and objectives of Faulkner (1981) reinforce the argument that the author tends to believe in the transformational view that 'competence' is superior to 'performance' and that 'once competence has been acquired, performance will take care of itself' (Widdowson 1979:49). Support for this claim is given by the author's very statement that 'A study of sentence structure is necessary part of any basic course in composition' (p. vii).

Such an approach to composition writing is over-simplistic in that the sentence and composition are two different entities. Thus, the skills needed to write a good sentence are different from those needed to write a composition. What is more, it has been repeatedly reported above that it was dissatisfaction with the study of the sentence as the basic unit of linguistic structure that led to the emergence of the theory of discourse analysis (cf. Connor 1996). Some linguists have gone so far as to talk about text grammar to show that even when grammar is relevant to language use in general, it must operate at the text level (Van Dijk 1972).

All the sociolinguistic approaches that relate to Halliday's 'systemic theory' and Hymes' model of 'communicative competence' have been of the view that mere acquisition of linguistic competence does not necessarily produce good communicators (Allwright 1979, Widdowson 1979, McDonough and Show 1993, Couture 1986). These linguists differentiate between two facts that should be integrated so that effective communication can take place: knowledge of language structure and awareness of socio-cultural rules. Of course, the textbook under consideration did not allow for these developments in the linguistic theory despite the fact that it was contemporary with their beginnings in the 1960s. It could not, therefore, provide sound writing practice in the post-discourse era.

The book, needless to say, follows from a bottom-up approach to writing. Viz. since writing good sentences is central to composition writing, the book assumes, the students should be sufficiently taught about the sentence structure before they can proceed to compose at paragraph and essay levels. However, such an approach to writing is less than satisfactory since acquisition of correct structures is open-ended. It is well-known in the transformational literature that grammatical rules are finite but can generate infinite grammatical structures both in terms of the number of sentences or sentence length produced by a given grammar rule (cf. Radford 1986). So it would take the student a lifetime to acquire enough grammar to write correctly. It is clear, then, that this textbook is hardly relevant to the specific course objective which has been clearly set as: 'since the study of sentence structure is inseparable from any basic composition course, such study must be profound rather than shallow, preparing the student for the next writing course in level two'. It is unfortunate that experience does not seem to support this intention. To date no teacher's report (verbal or written) has indicated that the students did benefit from this book in improving their composing skills in the next writing course. In fact, there are many dissenting voices concerning the textbook's relevance among the teachers. The subsequent writing course concentrates more on composing processes and paragraph development in ways that hardly rely on the "basic skills" acquired from this book. 


\section{Conclusion}

As a practical activity, language teaching is assumed to 'draw on insights from many disciplines' (Brumfit and Johnson, 1979). Linguistics has been a major discipline to fuel classroom activities. Where writing is concerned, it was once practised as 'sentences in isolation', to use Widdowson's (1979) terms, at times when the dominating schools of linguistics approached the sentence as the basic unit of language. The second half of the $20^{\text {th }}$ century witnessed new developments into the linguistic theory whereby the 'text' has come to be viewed as the basic unit of language. Once again writing pedagogy has been greatly influenced in that classroom activities have focused on the paragraph as a unit of writing. Examination of the writing syllabus of some Arab universities has shown that writing practice assumes a bottom-up approach, emphasizing the sentence and its constituents at the expense of the skills needed to write coherent paragraphs. Thus, since the sentence and the paragraph are two different levels of linguistic representation, the current writing syllabus cannot be expected to improve learners composing skills at textual level.

\section{References}

Al-Hazmi, S. (2006). Writing Reflection: Perceptions of Arab EFL Learners. South Asian Language Review, XVI (2), 36-52

Al-Hazmi, S. And P. Schofield (2007). Enforced Revision with Checklist and Peer Feedback in EFL Writing: The Example of Saudi University Students. Scientific Journal of King Faisal University (Humanities and Management Sciences), 8 (2), 237-267

Al-Khuweileh, A. A. and A. Al-Shoumali (2000). Writing Errors: A study of the Writing Ability of Arab Learners of Academic English and Arabic at University [Abstract]. Language, Culture and Curriculum, 13 (2), 174-183. [Online] Available: http://www.informaworld.com/smpp/content

Al-Jamhoor, A. (2001). A Cross-Cultural Analysis of Written Discourse of Arabic- Speaking Learners of English. Journal of King Saud University (Language and Translation), 13(1), 25-44.

Allwright, R. (1979). Language Learning Through Communicative Practice. In C. I. Brumfit and K. Johnson (Eds.), The Communicative Approach to Language Teaching, (pp. 167-181). Oxford: Oxford University Press.

Brandt, J. (1986). Text and Context: How Writers Come to Mean. In B. Couture (Ed.), Functional Approaches to Writing: Research Perspective, (pp. 93-107). London: Frances Printer

Connor, U. (1996). Contrastive Rhetoric: Cross Cultural Aspects of Second Language Writing. Cambridge: Cambridge University Press.

Daoud, S. A. (1998). How to Motivate EFL Learning and Teaching of Academic Writing by Cross-Cultural Exchanges. English for Specific Purposes, 17 (4), 391-412.

Fitze, M. and R. Glasgow (n.d.). Input Enhancement and Tense Formation in Arab EFL Writing. Retrieved from http://www.tesoljournal.com/Articles/Example_Article.doc.

Freedman, A., I. Pringle, Y. Yalden (Eds.) (1983). Learning to Write: First Language/Second Language, (pp. 179-189). New York: Longman.

Harsh, W. (1982). Linguistics and TESOL: A Turbulent Twenty Years. Forum, xx (v), 2-8.

http://www.aui.ma/VPAA/LanguageCentre/awt1001.htm.

http://www.just.edu.jo/FacultiesandDepartments/FacultyofScienceandArts/Departments/EnglishforAppliedStudies/L ists/Courses/StudentView.aspx.

http://colleges.ksu.edu.sa/Arabic\%20Colleges/Arts/English/englishdepartment1/Pages/BAinarts.aspx

Hymes, D. (1979). On Communicative Competence. In C. I. Brumfit and K. Johnson. (Eds.), The Communicative Approach to Language Teaching, (pp. 5- 26). Oxford: Oxford University Press.

Jordan, R. R. (1997). English for Academic Purposes. Cambridge: Cambridge University. Press.

Krashen, S. D. (1984). Writing Research: Theory and Applications. Oxford: Pergamon Press.

McDonough, J. and C. Show. (1993). Materials and methods in ELT: A Teacher's. Guide. Oxford: Blackwell.

McMillan Encyclopedia. (1986). London: McMillan Limited.

Peters, P. (1986). Getting the Theme Across: A Study of Dominant Function in the Academic Writing of University Students. In B. Couture (Ed.), Functional Approaches to Writing: Research Perspectives, (pp. 169-185). London: Frances Printer.

Radford, A. (1986). Transformational Grammar. Cambridge: Cambridge University Press.

Raimes, A. (1987). Why Write? From Purpose to Pedagogy. Forum, xxv (4), 36-41.

Rivers, W. (1981). Teaching Foreign Language Skills. (2 ${ }^{\text {nd }}$ ed.). Chicago: University of Chicago Press.

Silva, T. (1990). Second Language Composition Instruction: Developments, Issues and Directions. In B. Kroll (Ed.), Second language writing: Research Insight for Classroom, (pp. 11-23). Cambridge: Cambridge University Press. Van Dijk, T. A. (1972). Some Aspects of Text Grammars: A Study of Theoretical Linguistics and Phonetics. The Hague: Mouton. 
Widdowson, H. (1979). Directions in the Teaching of Discourse. In C. J. Brumfit and K. Johnson (Eds.), The Communicative Approach to Language Teaching, (pp. 49-60). Oxford: Oxford University Press.

X, G. Q. (1991). The Major Concerns of Text Linguistics and Their Relevance to the Teaching of Writing. ERIC Document Reproduction Service No. 338060

Zamel, V. (1983). The Composing Processes of Advanced ESL Students: Six Case Studies. TESOL Quarterly, 17 (2), 165-186.

Table 1. Components of the Writing Courses

\begin{tabular}{|l|l|l|}
\hline $\begin{array}{l}\text { Eng. 111: Basic Language Skills } \\
\text { (King Saud University) }\end{array}$ & $\begin{array}{l}\text { ENG. 115: Writing (1) } \\
\text { (Jordan University of Science and } \\
\text { Technology) }\end{array}$ & $\begin{array}{l}\text { AWT10001: Academic Writing (1) } \\
\text { (Al-Kahayan University, Morocco) }\end{array}$ \\
\hline $\begin{array}{l}\text { Modal auxiliaries } \\
\text { Present and past perfect }\end{array}$ & Pronouns \\
Nouns & The topic sentence \\
Passive sentences & Coordination & Dependent and independent sentence \\
Adjectival clauses & Description & Pasic sentence types \\
Noun clauses & Fragments & Combining sentences and clauses \\
Direct and indirect speech & Subordination & Pre-writing strategies \\
Using 'if' & Modifiers & Writing a paragraph \\
Sentence patterns & Parallelism & Types of paragraph \\
Connecting idea & Comparison and contrast & \\
& Correlative conjunctions & \\
& Punctuation & \\
\hline
\end{tabular}

